\title{
Epidemiology and Histology Aspects of Breast Cancers of Women in Ivory Coast
}

\author{
Justin N'Dah Kouame ${ }^{1}$, Emile Troh ${ }^{1}$, Emmanuel Koffi Kouakou ${ }^{2}$, Brahima Doukouré ${ }^{1}$, \\ Arthur Didier Kouame ${ }^{3}$, Alain Didier Abouna ${ }^{1}$, Benjamin Ahoua Effi ${ }^{4}$, Mohenou I. Diomandé ${ }^{1}$ \\ ${ }^{1}$ Department of Pathology of the University Teaching of Cocody, Abidjan, Ivory Coast; ${ }^{2}$ Department of Pathology of the University \\ Teaching of Treichville, Abidjan, Ivory Coast; ${ }^{3}$ Department of Gynecology of the University Teaching of Cocody, Abidjan, Ivory \\ Coast; ${ }^{4}$ Department of Pathology of the University Teaching of Bouake, Abidjan, Ivory Coast. \\ Email: docteurnkj@yahoo.fr
}

Received August $6^{\text {th }}, 2012$; revised September $9^{\text {th }}, 2012$; accepted September $20^{\text {th }}, 2012$

\begin{abstract}
Breast cancer is a major public health problem both in developed countries, where it represents the first female cancer, and in developing countries, where its incidence is increasing. Purpose: The authors report the results of a study whose objective was to describe the epidemiological and pathological features of women's breast cancers in Ivory Coast. Material and Methods: This is a retrospective descriptive study on breast cancer histologically confirmed and made from the records of pathology laboratories of the University Hospital in Abidjan. The study period was 24 years (1984-2007). The parameters studied were: frequency, age, risk factors, the macroscopic and histological aspects. Results: Women's breast cancer was the second cancer among women (13.69\%) after cervical cancer and represented $6.51 \%$ of cancers. The average age was 45.21 years ranging from 10 years to 85 years. Subjects from 35 to 44 years were the most affected $(30.7 \%)$ and $8 \%$ of patients were under 30 years $(n=61)$. Multiparity $(53.55 \%)$ and lower socioeconomic level $(79.63 \%)$ were associated. At the macroscopic level nodular aspects represented $47.62 \%$ of cases $(n=301)$. Carcinomas were $92 \%(n=710)$ of histological types with $94.36 \%(n=692)$ of invasive carcinomas. Sarcomas $(5.7 \%)$, lymphoma (2.1\%) and Paget's disease $(0.3 \%)$ were also observed. With regard to prognostic, the grading of Scarff-Bloom and Richardson showed 26.75\% $(\mathrm{n}=156)$ grade I, $60.64 \%(\mathrm{n}=354)$ grade II and $12.52 \%(\mathrm{n}=73 \%)$ grade III. Conclusion: In consideration of prognosis of advanced forms, an effort should be made for diagnosis and early treatment of women's breast cancer in Ivory Coast.
\end{abstract}

Keywords: Cancer; Breast; Epidemiology; Pathology; Ivory Coast

\section{Introduction}

Breast cancer is the most common cancer of women worldwide and represents approximately $16 \%$ of all female cancers. According to WHO, 519,000 women died in 2004 and $69 \%$ of cancer deaths are from breast [1]. This is a complex disease influenced by many risky factors. We distinguish the genetic, environmental and demographic factors on the one hand. And on the other hand, the hormonal factors and those related to reproduction, lifestyle and eating habits. Clinically, it manifests itself as a breast lump sometimes associated with mastodymia, nipple discharge and retraction with axillary nodes affected in advanced forms.

In developed countries, screening by imaging and needle biopsy allow the diagnosis of cancerous lesions to be earlier and as a result terrible prognosis [2]. In developing countries, incidence rates are low but rising steadily with a tendency to become a public health pro- blem. The prognosis is bleak because of the lack of appropriate strategies in most of these countries [1]. In Ivory Coast, the advent of infectious diseases (HIV/ AIDS, malaria and endemic and epidemic diseases) and their corollaries on the ivorian population, has put in the background women's breast cancer [3]. For decades, the laboratory of pathological anatomy of Hospitals and University of Cocody and Treichville were the only ones in the Ivory Coast to perform examinations of pathological anatomy until the 1990s. A study conducted in those laboratories between 1974 and 1983 by Diomandé et al. showed that cervical cancer was the first cancer of women and breast cancer was the second with a frequency of $10.52 \%$ of cases [3]. According to an exhaustive study of the first results from the cancer registry of Abidjan carried out by Echimane et al., breast cancer of women has an incidence of 24.5 cases per 100,000 women [4]. The aim of our study was to clarify the epidemiological and pathological features of breast cancers 
of women in order to adopt an adequate strategy of care in our Ivorian context.

\section{Material and Methods}

This is a retrospective descriptive study conducted from registers of pathological anatomy laboratory of the University Hospital of Cocody and Treichville from 1984 to 2007. These laboratories were the main structures of registration and diagnosis of breast lesions in Ivory Coast. Databases reported in the records included the patient's identity (name, surname, age, sex and address). The clinical, personal and family history, place of origin, the type of sample, and histological types were recorded. They stem mainly from pathologic examination bulletins prefilled by the requesting physician or from the service. Initially, samples were fixed in $10 \%$ formalin and underwent the usual techniques of paraffin embedding, microtome cutting, staining with hematoxylin-eosin staining and additional colorations were absolutely necessary to refine the diagnosis. In our study were included all cases of breast cancers diagnosed on biopsy specimens of breast and pieces of partial or total mastectomy with or without cleaning out the axillary ganglia and histological examination confirmed. The results of breast needle biopsy unconfirmed in the pathologic examination were not considered. Multiple registrations of the same patient were considered only once. Statistical processing and data analysis were performed using SPSS software.

\section{Results}

\subsection{Epidemiology}

\subsubsection{Frequency}

From 1984 to 2007, we have worked in 139,542 samples and diagnosed 11,854 cancers, wich was a frequency of $8.5 \%$ of cases. Breast cancers of women represented $13.69 \%(\mathrm{n}=772)$ of cancer among women and $6.51 \%$ of all cancer patients together (men and women). The annual incidence was 30.33 cases with a peak in 2001 (50 cases). The frequency breaking down by year is illustrated in Figure 1.

\subsubsection{Age}

The average patient age at the moment of the diagnosis was 45.21 years ranging from 10 years to 85 years. The breaking down of ages is illustrated in Figure 2. The peak incidence was noted with patients from 35 to 44 years with a percentage of $30.7 \%(n=237)$. The subjects under 30 years represented $7.9 \%(n=61)$, those from 30 to 64 years $79.53 \%(\mathrm{n}=614)$ and aged patients $12.57 \%$ $(\mathrm{n}=97)$.

\subsubsection{Personal and Family History}

These personal and family histories are reported in Table

1. There was a high multiparty $(53.55 \%)$ among breast cancer patients. Precocious puberty was observed in $11.29 \%$ of patients $(\mathrm{n}=27)$, exclusive breastfeeding in $10.46 \%(\mathrm{n}=25)$ and family history of breast cancer based only on data of the interview in $8.78 \%$ of cases (n $=21)$. The first pregnancy after age 30 years old represented $4.18 \%(\mathrm{n}=10)$ and late menopause after 50 years old in $1.25 \%$ of cases $(n=3)$. The average age of menopause was 50.3 years ranging from 45 to 52 years.

\subsubsection{Socio-Economic}

The subjects with low socioeconomic status (housewife and tradeswomen) represented $79.63 \%$ of cases $(\mathrm{n}=$ 559).

Officials, pupils and students and the retirees had a frequency of $20.37 \%(n=143)$.

Different socio-economic values are reported in Table 2.

\subsection{Pathology}

\subsubsection{Macroscopic Aspects}

Macroscopic aspects were performed with 632 patients.

These were nodular $(47.63 \%)$, ulcerative $(29.9 \%)$, infiltrative orange peel $(13.45 \%)$, scirrhous $(8.07 \%)$ and calcifications $(0.95)$.

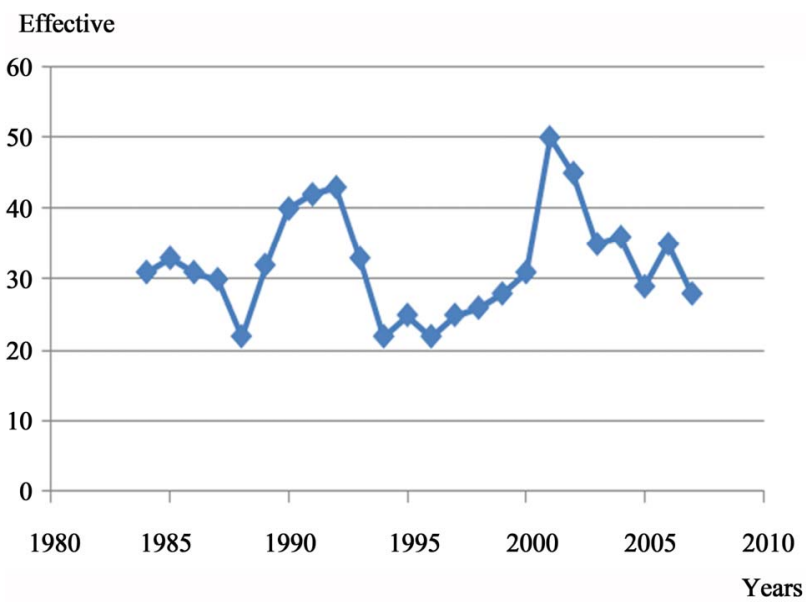

Figure 1. Distribution of frequencies by year.

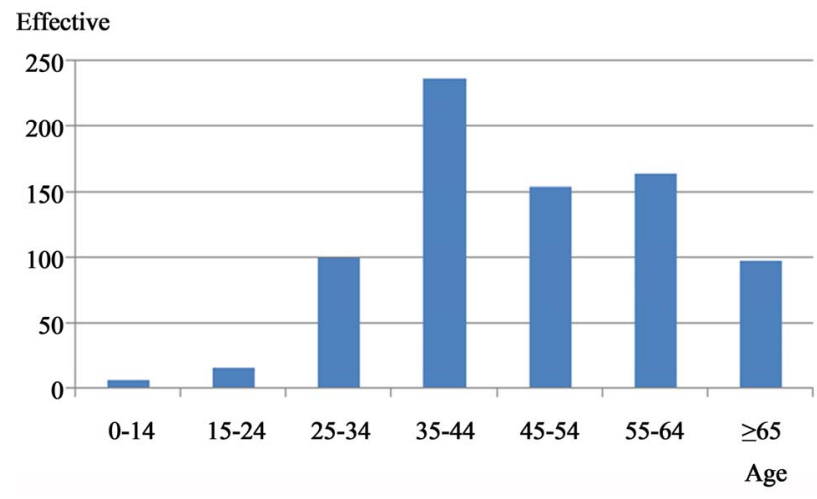

Figure 2. Distribution of breast cancer by age. 
Table 1. Different types of personal and family history.

\begin{tabular}{|c|c|c|c|}
\hline & ories & Effective & Percentage \\
\hline \multicolumn{2}{|c|}{ Precocious puberty } & 27 & 11.29 \\
\hline \multirow{3}{*}{ Party } & Nulliparity & 8 & \multirow{3}{*}{64.01} \\
\hline & Pauciparity & 17 & \\
\hline & Multiparity & 128 & \\
\hline \multicolumn{2}{|c|}{ First child after age 30} & 10 & 4.18 \\
\hline \multicolumn{2}{|c|}{ Exclusive breastfeeding } & 25 & 10.47 \\
\hline \multicolumn{2}{|c|}{ Late menopause after age 50} & 3 & 1.25 \\
\hline \multicolumn{2}{|c|}{ Family history of breast cancer } & 21 & 8.78 \\
\hline
\end{tabular}

Table 2. Different socio-economic levels.

\begin{tabular}{ccc}
\hline Socio-economic & Effective & Percentage \\
\hline Pupils and students & 23 & 3.28 \\
Officials & 107 & 15.24 \\
Housewife & 307 & $43 ., 73$ \\
Retired officials & 13 & 1.85 \\
Traders & 252 & 35.9 \\
Total & 702 & 100 \\
\hline
\end{tabular}

\subsubsection{Histological Aspects}

Their frequency is reported by Table 3 .

Carcinomas represented $92 \%(n=710)$ of histological types including $94.36 \%(\mathrm{n}=672)$ of invasive carcinomas.

Among these patients with carcinoma, 6.33\% $(\mathrm{n}=45)$ were under 30 years, $80.56 \%(\mathrm{n}=572)$ were aged between 30 and 64 and finally $13.1 \%$ were over 65 years.

There were also 20 cases of medullary carcinoma (2.59\% of cases) with an average age of 39.7 years. Sarcomas were observed in $5.7 \%$ of cases of histological types $(\mathrm{n}=44), 79.5 \%(\mathrm{n}=35)$ of Kaposi's sarcoma, $9.1 \%(\mathrm{n}=4)$ of malignant phyllode tumor, $6.8 \%(\mathrm{n}=3)$ liposarcoma and $2.3 \%(\mathrm{n}=1)$ of malignant hemangiopericytoma and fibrosarcoma.

Patients under 30 years accounted for $15.9 \%(n=7)$, whose age is between 30 and 64 years were observed in $75 \%(\mathrm{n}=33)$ and $9.1 \%(\mathrm{n}=4)$ for patients over 64 years.

As for lymphomas, their incidence was $2.1 \%(n=16)$ of histological types. We distinguished 11 cases of Burkitt lymphoma (68.75\%), 3 cases of large cell NHL $(18.75 \%)$ and 2 cases of NHL mixed with small and large cells (12.5).

These lymphomas were diagnosed in $50 \%$ of cases (n $=8$ ) among patients under 30 years and also in $50 \%$ of cases among patients from 30 to 64 years olds.

Paget's disease of the nipple was observed in $0.3 \%$ (n
$=2$ ) of histological types and in one case it was associated with infiltrating ductal carcinoma.

\subsection{Prognosis}

\subsubsection{Classification of Scarff Bloom Richardson Prognosis}

It was performed on 583 breast carcinomas. The grade I $(3,4,5)$ represented $26.75 \%(\mathrm{n}=156$ cases $)$, grade II $(6.7)$ $60.73 \%(\mathrm{n}=354)$ and grade III $12.52 \%$ of cases $(\mathrm{n}=73)$.

\subsection{2. pTNM Classification of Breast Carcinoma}

Their frequency is reported in Table 4. Lymph node metastases were observed in $86.44 \%$ of cases $(n=593)$. The average tumor size was $3.75 \mathrm{~cm}$ and ranged from 0.5 $\mathrm{cm}$ to $10 \mathrm{~cm}$.

\section{Discussion}

In Ivory Coast, for decades, cancer has been overshadowed by the importance of tropical infectious diseases. The country has only two laboratories of pathology located in Abidjan (economic capital). Inside the country the infrastructures to support the cancer patients do not exist and the absence of a pathologist contributes further to aggravate the prognosis. The subjects are referred to the only oncology department located in Abidjan. Samples from within the country are increasingly rare because of the increasing poverty of the population, which greatly influences the running of the single cancer Registry established in 1994 in Abidjan. Since the 1970s, the pathology laboratories of the University Hospital of Cocody and Treichville allowed to appreciate assess the impact of cancer. Although the values of these two laboratories only partially reflect the reality on the Ivorian breast cancer, they allow to notice the importance of this cancer that is increasing in our country $(13.67 \%$ in 2010 in our compared study to the series of Diomandé (10.52\% in 1988) [3]. This increased incidence is due to the improved diagnostics and especially the advent of mammography that few patients have access in Ivory Coast. We treated an average of 30 cases/year of breast cancer in our series. However, the absence of prevalence study is a real problem for the accurate assessment of this disease. An exhaustive study archived with the first results of Abidjan's cancer registry by Echimane et al. reported a standardized incidence of 24.5 per 100,000 women [4]. The average age at the moment of the diagnosis is earlier ( 45.21 years). Indeed about $8 \%$ of cancers occurred among patients under 30 years, $30 \%$ of patients were aged between 35 to 44 and about $12 \%$ of patients were over 64 years (older women). This distribution of slices ages is similar to that found in West African countries where the population is predominantly young $[5,6]$. The average age of our patients is identical to that ob- 
Table 3. Distribution of histological types according to age.

\begin{tabular}{lcccccccccc}
\hline Age histological types & $0-14$ & $15-24$ & $24-34$ & $35-44$ & $45-54$ & $55-64$ & $\geq 65$ & Total & $\%$ \\
\hline & IDC & - & 6 & 35 & 128 & 85 & 88 & 78 & 420 \\
& DCIS & - & 1 & 3 & 3 & 2 & 1 & - & 10 & \\
\multirow{2}{*}{ Carcinoma } & ILC & - & 3 & 38 & 76 & 57 & 59 & 14 & 247 & 92 \\
& LCIS & - & - & 2 & 5 & 1 & - & - & 8 & \\
& MC & - & 1 & 3 & 8 & 2 & 5 & 1 & 20 & \\
& ACC & - & - & - & 1 & 2 & 2 & - & 5 & 5.7 \\
Sarcoma & & 1 & 3 & 12 & 11 & 5 & 8 & 4 & 44 & 2 \\
Lymphoma & 5 & 1 & 5 & 4 & - & 1 & - & 16 & 2 \\
Paget's desease & & - & - & 1 & 1 & - & - & - & 2 & 0.3 \\
Total & 6 & 15 & 99 & 237 & 154 & 164 & 97 & 772 & 100 \\
\hline
\end{tabular}

Note: IDC = Infiltrating ductal carcinoma; ILC = Infiltrating lobular carcinoma; $\mathrm{MC}=$ Medullary carcinoma; ACC = Adenoid cystic carcinoma; NHL = Non-Hodgkin lymphoma; DCIS = Ductal carcinoma in situ; LCIS = Lobular carcinoma in situ .

Table 4. Distribution of breast cancer according to the pTNM.

\begin{tabular}{cccccccc}
\hline $\begin{array}{c}\text { Nods } \\
\text { tumor }\end{array}$ & $\mathrm{pN} 0$ & $\mathrm{pN} 1$ & $\mathrm{pN} 2$ & $\mathrm{pN} 3$ & $\mathrm{pNx}$ & Total & Percentage \\
\hline pT1 & 12 & 2 & 1 & - & 10 & 25 & 3.65 \\
pT2 & 27 & 41 & 30 & 15 & 17 & 130 & 18.95 \\
pT3 & 31 & 47 & 80 & 27 & 42 & 227 & 33.09 \\
pT4 & 15 & 48 & 57 & 24 & 57 & 201 & 29.3 \\
pTx & 8 & 33 & 17 & 19 & 26 & 103 & 15.01 \\
Total & 93 & 171 & 205 & 85 & 152 & 686 & 100 \\
$\%$ & 13.55 & 24.93 & 29.88 & 12.39 & 22.15 & 100 & \\
\hline
\end{tabular}

served by Najjar et al. [7] (45.4 years) and different from data given by Rahasolo in Madagascar (47.5 years) [8], Traore in Mali (48.2 years) [5] and European and US averages (60 to 65 years) [9]. In general, the everage age for diagnosis of breast cancer in developing countries is lower than in western countries with an increasing trend in all African series $[5,6,8]$. Thus, many genetic risk factors, environmental, demographic, sanitary and hormone have been incriminated in breast carcinogenesis. The early menses, associated with early and prolonged exposure to hormonal impregnation, is not frequent in our study and would be related to eating habits and requirements of the westernization of urban populations [10]. Exclusive breastfeeding, long practiced in developing countries, permitted to reduce considerably the development of breast cancer through the resting ovaries [10]. Unfortunately, the present context of modernization of Ivorian society explains the gradual forsaking of this type of plan in favor of mixed feeding and artificial and is actively involved in the occurrence of breast cancer the woman. Family history of breast cancer is often linked to major genes (BRCA1, BRCA2) and other genes such as TP53, PTEN, which are responsible for the Li-Fraumeni syndrome and Cowden disease [11]. Although, they have not been confirmed at the cytogenetic and molecular biology, familial breast cancers are not a significant entity in our series $(8.78 \%)$. The rate of menopausal women in our study remains low as reported in other low-incidence countries $[5,6,10]$. Most patients have significant physical activity (housewives and traderswomen). But according Friedenreich et al., physical activity has an influence on the risk of breast cancer by decreasing estrogen production and maintaining energy balance [12]. But the lack of strategy against breast cancer and lack of knowledge of breast cancer in a large majority of women, even urban, could explain this paradox. At macroscopic, the tumor nodules and ulcerated tumors formed the basis of macroscopic aspects, with an average size above than $3 \mathrm{~cm}$ in diameter. According to pTNM classification (2003) used in our study [13], 29.3\% of patients had tumors larger than $5 \mathrm{~cm}$ in diameter and lymph node involvement was observed in $86.44 \%$ cases. These values reflect the advanced stage of breast cancer in our country. Indeed, patients are seen in consultation in the context of advanced cancer very often after approximative diagnosis and generally often traditional treatment with herbal. Histologically, the predominance of epithelial tumours is similar to literature data $[5,6,14,15]$. Invasive carcinomas, which constitute the essential cancers, reflect the impact of the late diagnosis of this disease in Ivory Coast. The poor prognosis of these tumors is conformed with the african literature $[5,6,8]$. Breast sarcomas $(5 \%$ of all histological types) are mainly Kaposi's sarcoma (79.5\% 
sarcomas) in our country. This is a situation due to the impact of the virus HIV/AIDS, most often responsible for carcinogenesis of tumor whose incidence remains high in Ivorian society [16]. Primitive non-Hodgkin lymphomas have also been identified; the most common is an endemic Burkitt lymphoma (68\% of cases). Indeed, the incidence of lymphoma B is high in African countries located under the Sahara. In Coast Ivory, it particularly affects children and adolescents and represents for 30 to $60 \%$ of childhood cancers with a predominant localization in the mandible [17]. These locations extra-atypical mandibular and abdominal are rare in the literature and could be due to a spreading of tumor cells from an unknown site to the mammary vessels. The high rate of breast cancers among patients under 30 years observed in our study is related to the impact of these two endemic diseases in Ivory Coast.

\section{Conclusion}

Breast cancer is a common disease in the Ivory Coast and is therefore a major public health problem. It is a disease that primarily affects young individuals and is most often diagnosed at an advanced stage. In consideration of the poor prognosis of breast cancer of women in our country, an effort should be made for the setting up of information programs and training of women (breast self-examination), health workers and medical practitioners (gynecologists) throughout the territory. The effectiveness of such a public health program must take into account both the training of specialists in pathology, and the creation of a radiotherapy and oncology equipped structure as part of a real testing policy of precancerous lesions and their management.

\section{REFERENCES}

[1] World Health Organization (WHO 2008), “The Global Burden of Disease," 2004 Update.

[2] H. Rochefort and J. Rouëssé, "Breast Cancer: Incidence and Prevention," Report of a Working Group of Committee III (Cancer), 2000, p. 22.

[3] I. Diomandé, A. F. D’Horpock, P. Heroin, M. Ette, A. Dago, F. Battesti, et al., "Evolution of Cancer in Ivory Coast," Medical Publication in Ivory Coast, Vol. 75, 1988, pp. 81-84.

[4] A. Echimane, A. Ahnoux, I. Adoubi, S. Hien, K. M'Bra, A. F. D'Horpock, et al., "Cancer Incidence in Abidjan, Ivory Coast. First Results from the Cancer Registry, 1995-1997," Cancer, Vol. 89, No. 3, 2000, pp. 653-663. doi:10.1002/1097-0142(20000801)89:3<653::AID-CNCR 22>3.0.CO;2-Z

[5] M. Traore, F. S. Diabate, I. Diarra, N. Mounkoro, Y. Traore, I. Tekété, et al., "Breast and Gynecologic Cancer at the Hospital from the Point G in Bamako," Medical Publication in Mali, Vol. 19, No. 2, 2004, pp. 4-9.

[6] D. Sano, R. Cissé, B. Dao, J. Lankoandé, S. S. Traore, R. B. Soudré, et al., "Breast Cancer, Diagnostic and Therapeutic Problems at the Hospital of Ouagadougou," Medical Publication in Subsaharan Africa, Vol. 45, No. 5, 1998, pp. 297-301.

[7] H. Najjar and A. Easson, "Age at Diagnosis of Breast Cancer in Arab Nations," International Journal of Surgery, 2010, [Epub ahead of print].

[8] C. R. Raharisolo Vol.olonantenaina, L. P. Rabarijiaona, C. Rajemiarimoeisoa, M. Rasendramino and R. Migliani, "Assessment of Breast Cancers Diagnosed L'institut Pasteur de Madagascar from 1995 to 2001," Archives de L'Institut Pasteur de Madagascar, Vol. 68, 2002, pp. 104-108.

[9] D. Shaheenah, B. Kristine, A. Gonzalez, A. U. Busdor, N. Hortobagyi and H. G. Sharon, "Trends in Survival over the Past Two Decades among White in Black Patients with Newly Diagnosed Internship IV Breast Cancer," Journal of Clinical Oncology, Vol. 26, No. 30, 2008, pp. 4889-4899.

[10] C. A. Adebamowo, S. N. Akarolo-Anthony and O. O. Temiayo, "Emerging Epidermic Breast Cancer: Evidence from Africa," Breast Cancer Research, Vol. 12, Suppl. 1 4, 2010, p. S8. doi:10.1186/bcr2737

[11] A. Antoniou, P. D. Pharoah, S. Narod, H. A. Risch, J. E. Eyfjord, J. L. Hopper, et al., "Average Risks of Breast and Ovarian Cancer Associated with BRCA1 or BRCA2 Mutations Detected in Case Series Unselected for Family History: A Combined Analysis of 22 Studies," Erratum in: The American Journal of Human Genetics, Vol. 73, No. 3, 2003, p. 709.

[12] C. M. Friedenreich and M. R. Orenstein, "Physical Activity and Cancer Prevention: Etiologic Evidence and Biological Mechanisms," Journal of Nutrition, Vol. 132, No. 11,2002 , pp. 3456S-3664S.

[13] World Health Organization, "Tumors of the Breast and the Female Genital Organs," In: P. Deviled, Ed., Pathology and Genetics, IARC Press, Lyon, 2003, pp. 13-59.

[14] A. Laplanche and E. Benhamou, "Estimated Incidence of Cancer in France," Bull Cancer, Vol. 78, No. 5, 1991, pp. 505-514.

[15] E. Duarte-Franco and E. L. Franco, "Others Gynecologic Cancers: Endometrial, Ovarian, and Vaginal Cancers Vulva," BMC Women's Health, Vol. 25, Suppl. 11, 2004, S14. doi:10.1186/1472-6874-4-S1-S14

[16] D. M. Parkin, S. L. Whelan, J. Ferlay, L. Raymond and J. Young, "Cancer in Five Continents," IARC Scientific Publications, Lyon, Vol. 12, No. 143, 1997, pp. 35-36.

[17] A. B. Effi, K. J. N'Dah, A. A. N'Guiessan, B. Doukouré, M. Kouyaté, A. D. Abouna, et al., "Epidemiology and Pathology of Carcinoma in Ivory Coast," African Journal of Cancer, Vol. 4, 2012, pp. 41-47. doi:10.1007/s12558-011-0189-2 